\title{
Gloria o maldición del individualismo moderno según Louis Dumont
}

\author{
Verena Stolcke \\ Professora do Departamento de Antropología Social y Prebistoria - Facultad \\ de Letras - Universidad Autónoma de Barcelona
}

RESÚMEN: Este artículo discute la noción de individualismo en Louis Dumont, partiendo sobretodo de una reconstitución del encuentro entre sus perspectivas metodológica - que tiene como base el estudio antropológico de la civilización indiana - y teórica, referida a la relación entre individuo y sociedad en una llave propiamente maussiana. Por el hecho de saberse que Dumont se utiliza de un abordaje al mismo tiempo comparativo y estructural, lo que se busca es mostrar que el individualismo, al mismo tiempo que se presenta ideologicamente como opuesto a la jerarquía típica de sistemas como las casta indianas, mantiene propiedades lógicas semejantes, en lo que se refiere a la relación entre los valores y las prácticas sociologicamente "englobadas" y veladas. De este modo es posible entender, a partir de este pensamiento, como en el interior del mismo sistema individualista - liberal e igualitario - hay espacio para ideologías totalitarias y racistas, como perversiones jerárquicas que trabajan la desigualdad en planos sociologicamente asimétricos como la "naturaleza".

PALABRAS-LLAVE: Individualismo, jerarquía, igualdad, análisis comparativo y estructural.

De hecho, el totalitarismo expresa de forma dramática algo que siempre volvemos a encontrar en el mundo contemporáneo: que el individuo es, por una parte, todopoderoso y que, por otra, está perpetua e irremediablemente amenazado por su contrario. (Dumont, 1987: 27-8) 
La tesis radical que yo presento posee la virtud heurística de un paso hacia el límite (...) he evidenciado el carácter etnocéntrico o (...) sociocéntrico de muchos de nuestros universales, ingenuos o supuestos (...) la especialización antropológica corresponde a una especie de vanguardia necesaria en el movimiento de ideas (...) nosotros mismos nos vemos remitidos a nuestra propia cultura y sociedad moderna como a una forma particular de humanidad, que es excepcional debido a que se niega como tal en el universalismo que profesa. (Idem: 211-2)

El ensalzamiento neo-liberal de las lucrativas virtudes creativas del individualismo competitivo dota de especial actualidad la obra del antropólogo Louis Dumont, recientemente fallecido, un teórico del individualismo moderno tan innovador y sugerente como complejo y controvertido. La obra de Dumont es original en mas de un sentido. A diferencia de la antropología clásica dedicada a la investigación de "sociedades etnográficas" y de las incursiones postcoloniales de la disciplina en las sociedades "complejas", Dumont dedicó su vida al estudio comparativo de las grandes civilizaciones. En vez de centrar su atención en los hechos sociales, las morfologías o la acción social de la modernidad, despliega su análisis al nivel de las ideologías, de los sistemas de ideas-valores que dotan a distintos modos de convivencia humana de significados contrastantes. Como antropólogo estaba convencido que "el respeto por el otro pasa por el respeto de los valores que subyacen a la vida de toda sociedad humana. La sociedad no es solamente una sección particular de la naturaleza ni una suerte de residuo despojado de significado propio, de pretensiones individuales. La sociedad es significado, dominio y condición de significado" (Dumont, 1987, énfasis mío). Diferentes civilizaciones se distinguirían por su modo particular de concebir el lugar del individuo en relación a la sociedad. Pero Dumont no tenía ningujna simpatía por el relativismo cultural banal. Para comprender cambiantes concepciones del individuo "pone en perspectiva" el individualismo occidental observándolo desde el holismo que caracteriza el sistema de castas en la India tradicional. Este ambicioso programa comparativo le conduce, a su vez, a una crítica metodológica y epistemológica de la 
Revista de Antropologia, São Paulo, USP, 2001, v. 44 nº 2.

antropología social y la sociología convencionales que desembocará en una suerte de perspectivismo comparativo - Dumont lo denomina una sociología comparativa - que nada tiene que ver con el individualismo ni el holismo o sociologismo metodológicos sino que se entiende como alternativa metodológica para confrontar el problema de la relación entre individuo y sociedad que es la marca indeleble de la modernidad.

La antropología social aporta una perspectiva comparativa a su objeto. Pero al contemplar la trayectoria intelectual de Dumont viene a la mente la imagen de una espiral. Las ideas fundamentales no suelen llegar acabadas al primer golpe sino que se ramifican y adquieren profundidad gradualmente (1970: 11). Dumont hace alarde de un despliegue dialéctico y creativo de ideas desde que inicia su formación como etnólogo e indianista en la escuela sociológica de Durkheim y Mauss, pasando por su experiencia iniciática etnográfica en la India, cuyo sistema socio-ideológico le reveló, como si fuese un espejo, la peculiaridad excepcional del individualismo moderno, cuyo puesta en perspectiva recíproca lleva Dumont a arraigar la propia antropología social en la modernidad y a desafiar el mismo método antropológico.

Ese ir a venir entre dos formas distintas de civilización y entre ellas la modernidad occidental y su postulada universalidad y voluntad globalizadora, colocan la obra de Dumont de cierto modo por encima del tema del individualismo moderno. La modernidad no constituye para él objeto de sospecha como lo es, por ejemplo, para los deconstructivistas o postmodernos, sino que es de manera muy fundamental, la interrogante de un problema - la relación individuo/sociedad en la ideología moderna - que Dumont antropólogo, mas que explicar, desea y confía comprender desde un punto de vista descentrado. La modernidad de la antropología social hace de ella una herramienta de investigación que, no obstante, debe ser ella misma perpetuamente interrogada. Una reflexión constante sobre los modos de pensar "modernos" es inseparable de la investigación antropológica. 


\section{De Dumont, el aprendiz de antropólogo}

Louis Dumont murió en Paris en noviembre de 1998 a la venerable edad de 87 años, después de una larga y fructífera aunque solitaria carrera académica. Fue un antropólogo de grandes ambiciones y controvertidas aportaciones intelectuales que siempre defendió su independencia intelectual celosamente y rehuyó los cánones y categorías analíticas instituidas. No tuvo pelos en la lengua para criticar sin concesiones a la disciplina y la profesión aunque fue un hombre discreto y modesto. Su postura intelectual "excéntrica" para la época, le produjo un cierto aislamiento en la universidad en ese mundillo académico de escuelas y lealtades habitualmente fragmentadas y enfrentadas. Salvo un fiel grupo de discípulos y seguidores pocos fueron sus colegas franceses que compartiesen sus propuestas teóricas y epistemológicos. Los historiadores y sociólogos, en cambio, se interesaron por sus interpretaciones sobre todo de la génesis histórica del individualismo moderno, por su distinción conceptual entre estatus social y poder, su reconstrucción de la emancipación del poder político en occidente del dominio religioso al quedar la Iglesia supeditada al poder del Estado secularizado.

Dumont supo compaginar, no obstante, su atrevida amplitud de miras con el trabajo etnográfico paciente y minucioso, casi artesanal, que situó en un marco global y dotó de profundidad histórica empleando fuentes textuales. Aunque algunos críticos achacaran en especial a sus escritos sobre el individualismo moderno (Dumont, 1982, 1991), que salvo a algunos no hubiese leído en el original a los pensadores que analiza sino que utilizase comentaristas, es improbable que Dumont habría conseguido esa fascinante visión panorámica comparativa de la ideología moderna de otro modo.

Dumont no era un abstraído intelectual sin que fue un hombre de su tiempo comprometido con el desciframiento de los enigmas sociopolíticos del mundo que le tocó vivir. Su obra está marcada y refleja las esperanzas y las grandes tragedias de su siglo. Sirvan de ejemplo su 
ensayo sobre la "apocalipsis hitleriano" (1987: 157-86) o su creciente preocupación con las consecuencias culturales de la progresiva globalización económica (1975: 159).

De joven, en los años treinta, Dumont había frecuentado las vanguardias parisinas del cine y estaba próximo al Frente Popular, habiéndose afiliado al Partido Comunista a principios de la década. En aquellos años sombríos del fin de la entre-guerra eran pocos los etnólogos que tuviesen vínculos con el mundo artístico o político. Hubo excepciones como Michel Leiris, quien al distanciarse del movimiento surrealista también se aproximó al comunismo, o Paul Rivet, director del Musée d'Etnographie du Trocadero, precursor del Musée de l'Homme, quien fue candidato por el Partido Socialista del Frente Popular. Al igual que su contemporáneo Claude Lévi-Strauss, Dumont descubrió la etnología en 1939 en el seminario de Marcel Mauss en el College de France poco antes de que estallara la segunda gran guerra. El pensamiento de Mauss ejercería una profunda y duradera influencia intelectual sobre él (Dumont, 1987: 189-206) ${ }^{1}$.

Como ocurrió con otros antropólogos de su generación, la guerra mundial trastocó también la vida y la carrera profesional de Louis Dumont aunque él tal vez tuviese mas suerte que otros en esa desgracia ${ }^{2}$. Al caer prisionero en el norte de la Borgoña a principios de la guerra, los alemanes le enviaron a un campo de prisioneros en las cercanías de Hamburgo donde el trato no parece haber sido especialmente severo. Dumont pudo dedicarse a aprender alemán con una gramática que llevaba consigo, y al manifestar su interés por el sánscrito se le permitió estudiarlo con el profesor Schubring de la Universidad de Hamburgo a quien la guerra había privado de sus propios estudiantes.

\section{El gran comparador}

El trágico desmentido por el nazismo de los ideales ilustrados de igualdad y libertad y las represiones estalinistas reforzaron el desencanto 
político que Dumont ya había experimentado en la época del Frente Popular. Acabada la guerra abandonó el partido comunista y trasladó su labor crítica por entero al ámbito científico.

Al regresar de la guerra en 1944 se le ofreció la oportunidad de trabajar en el remozado Musée de l'Homme, dotado de una nueva sección de Artes y Tradiciones Populares, como secretario de GeorgesHenri Rivière, quien le sugirió que participase de un estudio sobre la cultura popular en Francia ${ }^{3}$. Fue así como Dumont adquirió su primera experiencia etnográfica en el sur de su propio país estudiando una fiesta popular. Los resultados están rfecogidos en la preciosa monografía $L a$ Tarrasque (Dumont, 1951). Pero no le interesaba a Dumont la cultura popular ni su estudio etnográfico en Francia aunque descubrió en la ocasión el valor de la observación etnográfica participante intensiva y riguroso. Quería estudiar fenómenos culturales distintos de lo que pudiese encontrar en Europa.

La idea clave de toda la obra de Dumont es la perspectiva comparativa y en ella reside parte de la originalidad de su enfoque de la ideología moderna. Esa perspectiva comparativa y relacional aplicada al plano de las ideologías constituiría el eje metodológico de sus investigaciones posteriores ${ }^{4}$. A diferencia de la casi totalidad de estudiosos del individualismo democrático, el pensamiento de Dumont de modo alguno se inscribe exclusivamente en la modernidad occidental. Por el contrario, accedió a la lógica excepcional de la ideología moderna, según él única en la historia del género humano, la centralidad en ella del individuo, el valor dado a la libertad y la igualdad, a través de un constante juego de espejos de referencias a civilizaciones distintas desprovistas de esta vocación individualista. Y sería en particular el sistema de castas de la India tradicional que se transformaría para Dumont en la imagen espejo privilegiada que le ayudaría a identificar e interpretar la singularidad de la ideología moderna occidental.

Concluida su formación como indianista clásico en Paris con Louis Renou a fines de los años cuarenta, Dumont preparó su primera expedición de trabajo de campo de envergadura trasladándose al sur 
de la India en 1949. Este primer viaje a la India y el estudio etnográfico de una subcasta, la de los Pramalai Kallar de Tamil Ñandú que resultaría una suerte de banco de prueba para un análisis de tipo estructuralista significó para Dumont el verdadero inicio de su aprendizaje como antropólogo. Dedicó la monografía sobre los Pramalai Kallar a LéviStrauss (Dumont, 1957). Aunque el vínculo amistoso y profesional con éste se enfriase con los años y Dumont se distanciase en lo metodológico poniendo el acento en los hechos etnográficos empíricos y en la sociedad en lugar de las estructuras profundas del "espíritu" humano que LéviStrauss buscaba documentar con el análisis estructural de fenómenos culturales, como se verá, el concepto de estructura lévi-straussiano continujará desempeñando un papel analítico destacado en la perspectiva comparativa de Dumont.

La decisión de hacer trabajo de campo en la India no fue casualidad. La opción etnográfica de Dumont por una realidad socio-ideológica tan distante y compleja como lo es el sistema de castas de la India, a parte de su formación como indianista y la influencia de Mauss, respondía también a lo que Lévi-Strauss había denominado "le privilège du dépaysement" (el privilegio del "despaisanamiento"): "ver las cosas desde afuera le obliga a uno a verlas de modo global". Como explicaría mas tarde, al regresar de la India, habiéndose él mismo "indianisado" un poco, pudo aplicar ese privilegio a su propia cultura y comprenderla en todo su misterio (Bruckner, 1992: 68). El programa de una sociología comparativa indo-europeo en líneas generales parece haber surgido, en efecto, de esa primera experiencia en la India que le conduciría al decisivo descubrimiento - que compartiría con Mauss y Polany (Polany, 1944) - de que existía una discontinuidad radical entre la modernidad y el resto de civilizaciones.

A partir de los años cincuenta Dumont insistió sistemáticamente que el estudio de la India tenía mucho que enseñar también a quienes investigasen en Europa u en otras partes del mundo. Dumont era muy crítico de la antropología comparada y las taxonomías al uso en la época 
por privilegiar las analogías de las similitudes y despreciar las lecciones de los contrastes y las diferencias culturales. La mayor parte de los etnólogos profesionales que en la época trabajaban en la India disociaban, además, la etnología de la indología, dedicándose, al igual que sus colegas en África, estudios de caso de "tribus", de grupos humanos supuestamente aislados y claramente circunscritos que ellos confiaban estaban exentos de las influencias culturales de la civilización india. Dumont no era en absoluto adverso al trabajo etnográfico localizado pero estaba convencido de que para comprender situaciones sociales locales en la India, como en otros lugares, era imprescindible situar a éstas en el contexto global de la configuración de ideas-valores en que estaban inscritas, es decir, que había que conciliar la etnología con la indología. El gran desafío de la indología consistía precisamente en identificar y comprender esa "globalidad" (Dumont, 1957: 14) en cuyo interior se podrían estudiar las relaciones entre dimensiones culturales desde una perspectiva estructural en sociedades de la magnitud y complejidad de la India ${ }^{5}$.

En 1966, una escasa década mas tarde, Dumont publica Homo Hierarchicus, su estudio magistral del sistema de castas de la India tradicional en toda su complejidad ideológica estructural que descubriría la globalidad típicamente holista y jerárquica de la sociedad de castas $(1970)^{6}$. Homo Hierarchicus consagraría a Dumont como teórico de la antropología social porque provocó una una intensa y apasionada polémica política y profesional. Entre los indianistas clásicos la recepción fue en general favorable. Entre los antropólogos sociales, en cambio, las críticas fueron airadas en particular en el ámbito británico pues se sentían atacados de modo personal por las críticas de Dumont de su superficialidad teórica, su etno - y sociocentrismo metodológicos. Los sociólogos, en cambio, apenas tomaron nota de la obra (Dumont, 1979a; Béteille, 1986; Tcherkézoff, 1993).

Dumont abre su libro sobre el sistema de castas en la India con una cita de Alexis de Tocqueville referente a la posición del individuo en 
Revista de Antropologia, São Paulo, USP, 2001, v. 44 nº 2.

la democracia liberal de Estados Unidos según quien "la democracia rompe la cadena y separa todos los eslabones" (Dumont, 1970: 3). Pero esta alusión al individualismo liberal democrático no es mas que otra señal de su programa comparativa, y expresa la admiración que siente por Tocqueville y la habilidad de éste de comprender una sociedad (la francesa) a través del estudio de otra diferente (la de Estados Unidos).

¿Ahora bien, en qué consiste exactamente el perspectivismo comparativo de Dumont y qué papel juega la ideología moderna a este respecto? Durante los años setenta Dumont desplaza su atención analítica de modo progresivo pero definitivo de la India a Europa. Se trata de una decisión metodológica y epistemológica estratégica. Era preciso poner diferentes civilizaciones en perspectiva una con respecto a otra, en primer lugar, por ser la mirada etnográfica inevitablemente subjetiva. Al estudiar otra civilización, Dumont escribía en 1962 con respecto al enfoque que exigía el conocimiento de la India, era deseable en primer lugar "establecer una correcta relación intelectual entre nuestra propia civilización, que nos proporciona los modos de pensamiento, y la que nos esforzamos en captar". La idea que nos formamos de otra cultura no depende unicamente de los datos accesibles sino de nuestra forma de interpretar esos datos y de nuestra forma de pensar en general (Dumont, 1989: 13).

En segundo lugar, Dumont entrevió la peculiar lógica ideológica de la modernidad occidental al volver el espejo en el que se reflejaba a la India tradicional. Esa imagen de la India estaba mediada, no obstante, por el hecho de que su percepción como observador ya estuviese configurada por el problema característico de la modernidad occidental de la relación individuo/sociedad (Dumont, 1987: 195; Tcherkézoff, 1993: 205). Por consiguiente, aunque su punto de vista resultase en un principio de un azar, su encuentro con la India, la perspectiva comparativa que Dumont emplea nace del camino que recorre de la India hacia nosotros. Una vez puestos en perspectiva nosotros mismos, ciertos contrastes entre nosotros y los otros ayudarán a percibir la 
particularidad de los otros. Mismo que el punto de vista comparativo de Dumont pretendiese ser aquel de la India, en la práctica el que adopta es el de un occidental provisto ahora de nuevas percepciones ideológicas y sociológicas que adquirió allí.

En realidad se trata de un doble y recíproco trabajo de interpretación que, además y en tercer lugar, tiene importantes consecuencias para la propia antropología social. Al encargarle los Ensayos sobre el individualismo (1987), Paul Thibaud, de la revista Esprit, le había pedido expresamente que ofreciese una explicación de su transición de la antropología de la India al estudio de la modernidad occidental y la conexión de este desplazamiento etnográfico con su muy personal concepción de la antropología.

Según Dumont en la antropología nos encontramos, en efecto, de entrada en el nivel más radical de análisis pues ni puede hacerse abstracción del observador ni éste puede abstraerse de lo observado. La comparación de civilizaciones mediante su puesta recíproca en perspectiva "es radical, ya que pone en juego las concepciones del propio observador que, a mi juicio, dominan todo lo demás. Desde este punto de vista, la manera de concebirnos a nosotros mismos evidentemente no resulta indiferente. Por esta razón no es en absoluto una tarea superflua para la antropología un estudio comparado de la ideología moderna." (Dumont, 1987: 20-1). Para comprender su propio punto de vista Dumont decide, por lo tanto, estudiar el individualismo moderno que es también el punto de vista de la antropología social como disciplina típicamente moderna.

\section{Holismo y jerarquía versus individualismo, igualdad y libertad}

Hay una notable continuidad en la obra de Dumont al hilo de los años. La experiencia etnográfica en la India precede cronológica - y conceptualmente a su inmersión en la ideología occidental moderna. Pero la sociedad de castas de al India tradicional de punto de partida 
Revista de Antropologia, São Paulo, USP, 2001, v. 44 nº 2.

casi de inmediato se convierte en contrapunto analítico que iluminará la ideología moderna occidental. En la India Dumont todavía no tiene aún una idea precisa sobre como comparar el individualismo moderno con el sistema de castas pero ya entrevé esa comparación como prolongación lógica de su estudio de una sociedad cuyos rasgos morfológicos e ideológicos principales son el holismo y la jerarquía. La configuración de ideas-valores característica de la India tradicional se convierte así en el telón de fondo sobre el que acaba por destacarse lo novedoso y característico de la ideología moderna que, por el contrario, evoca al individuo y la igualdad como valores supremos.

En la introducción a Homo Hierarchicus Dumont señalaba que, "La apercepción sociológica se opera contra la visión individualista del hombre, y tiene como consecuencia inmediata la idea del individuo, constituido en problema de la sociología" (Dumont, 1970: 12). Alude con el término "apercepción sociológica" al hecho que Mauss había mostrado con anterioridad de que conceptos de persona, el individuo son construcciones socio-culturales. En contraste con el nominalismo individualista sociocéntrico de las ciencias sociales convencionales, Dumont recupera la contribución maussiana y adopta la distinción kantiana entre el individuo empírico, de "carne y huesos", presente en cualquier sociedad y la concepción histórica del individuo como "ser de razón", como ser moral, dueño de su propio destino y sujeto normativo de las instituciones. La sociedad moderna se desea racional al separarse de la naturaleza para instaurar un orden humano autónomo, y, por consiguiente, artificial (: 12 y 323). El poderoso contraste que Dumont descubre entre la India y la modernidad occidental reside precisamente en el lugar que asignan respectivamente al individuo en relación con la sociedad. Su interés por la "apercepción" del individuo se refleja ya en el análisis de la figura del renunciante en el hinduismo que sigue de inmediato a su primera primorosa etnografía de una sub-casta en el sur de la India (1957), donde muestra que la referencia al individuo está subordinada, es residual aunque no esté ausente pues aquel asceta 
puede y de hecho construye su destino religioso individual sólo saliendo del sistema de castas puede, como hombre-fuera-del-mundo ${ }^{7}$.

Esa primera experiencia etnográfica le revela que en la India la casta es el vínculo social determinante que se encuentra en la base de las relaciones sociales y pertenece al dominio de la organización social. El sistema de castas se define por la sumisión de los deseos de cada miembro a una jerarquía de carácter religioso que tiene su origen en la superposición del dominio religioso como fuente de autoridad y verdad al poder real terrenal. La jerarquía en cuanto gradación social es la clave de la representación colectiva del sistema de castas que está ordenada por la oposición entre "puro/impuro". Las castas ocupan lugares relativos al organizarse en el conjunto del sistema y reproducen en su interior el mismo principio jerárquico de unidad en un proceso de segmentación indefinida. Así, el principio de jerarquía es omnipresente en el sistema de castas aunque la ubicación de cada casta en la gradación sea relativa, la superioridad dependiendo del contexto en que ocurre la evitación de "contaminación" (se trate de los alimentos, de matrimonios o de funerales) mientras que la separación entre castas es inseparable de su interdependencia en el ámbito de la especialización de servicios.

Una vez identificado el principio de jerarquía que atraviesa el sistema de castas y el carácter orientado de todas las oposiciones que la estructuran Dumont extrapola una categoría en el plano de las ideas-valores aún más general, a saber, la ideología "holista" que definiría la sociedad de castas en última instancia. El sistema de castas se rige por una ideología "holista", en la medida en que el orden normativo le asigna el valor supremo a la totalidad social por encima del individuo a quien ignora. Por consiguiente, la pertenencia a la sociedad es lógicamente superior a sus consecuencias sociales. Aún así y a pesar de ese "holismo", como indiqué, la casta como relación social no agota la lógica social de la India tradicional. En un plano global hay otra relación en la cual reside, según Dumont, el secreto último del hinduism, a saber, la relación, o mejor dicho el "diálogo", que prevalece entre el renunciante y el hombre 
Revista de Antropologia, São Paulo, USP, 2001, v. 44 nº 2.

de casta. Las castas inferiores no están excluidas del mundo social sino que forman parte integral de la gradación simbólica y social de los servicios como hombres-en-el-mundo. El renunciante de la tradición hindú, en cambio, está y sólo puede estar fuera-del-mundo.

Dumont es consciente del problema metodológico que significa deducir una categoría general de ideología y sociedad de un solo caso estudiado así como tiene dudas sobre qué amplitud darle a esa categoría (Tcherkézoff, 1994: 203). Le cautiva, no obstante, la eficacia metodológica que tiene el "holismo" propio de la India tradicional para destacar la peculiaridad del individualismo moderno que precisamente en esa contraposición, aparece como fenómeno absolutamente excepcional y aparentemente único, debido a la penetración del individuo en el interior mismo del mundo social, a lo largo de la historia de las sociedades (Tcherkézoff, 1994: 204). Desde esta perspectiva la relación individuo/ sociedad que filósofos políticos y sociólogos occidentales modernos suelen problematizar aparece ahora como contrapunto ideológico de signo opuesto de la relación entre renunciante/miembro de la casta que Dumont descubrió en la India.

Gracias a su experiencia en la India Dumont pudo poner la modernidad en perspectiva y obtener así un punto de vista externo a ella. La antropología, en cambio, no había sabido como observar desde el exterior la configuración ideológica que la hizo nacer. Esta puesta en perspectiva de la modernidad le ayudó a Dumont, además, a precisar el marco teórico que exigía el estudio de la ideología moderna. La India le había proporcionado el redescubrimiento de la jerarquía en un plano teórico global, un concepto que efectivamente resultaría fundamental para "la comparación radical, en la que nosotros mismos estamos implicados" (Dumont, 1987: 21-2, mi énfasis).

La complejidad del concepto dumontiano de jerarquía y la confusión a que ha dado pie con la desigualdad socio-económica, con la que de hecho nada tiene que ver, seguramente explican en parte la impopularidad de la noción (: 228) Para Dumont la jerarquía no se refiere a una forma 
de realización de la desigualdad política o económica ${ }^{8}$. Él introduce la noción de jerarquía en dos sentidos distintos aunque relacionados. En un nivel social concreto, en la India prevalece la jerarquía de castas que obedece al principio de relatividad estructural. En un plano superior, externo al sistema de castas, está la jerarquía como valor trascendente que envuelve al anterior. Quiere decir, la jerarquía como principio unificador no se encuentra en el interior de los elementos del sistema (las castas) sino fuera de ellos en un plano superior que irremediablemente ordena los elementos de la totalidad social, pero que además - y esto es de importancia crucial - se expresa en la interdependencia característica de la India tradicional entre la esfera social y la religiosa y que dota a esta última de autoridad por encima del poder real. En otras palabras, la religión supedita al poder. Dumont definió el vínculo que existe entre ambos planos de la jerarquía como una relación estructural entre "englobante" y "englobado" (Dumont, 1979b: 396-403; volveré a esta cuestión). Cómo bien señaló Galey, es a este nivel de la jerarquía en cuanto principio unificador del sistema de castas cuya legitimidad deriva de su inscripción en un orden religioso trascendental, que se contrapone el principio unificador del universo individualista moderno el cual dota, por el contrario, al individuo de un valor trascendental y absoluto en su afán de minimizar lo social suprimiendo o mejor dicho reprimiendo el hecho de la apercepción sociológica del individuo (Galey, 1984: xxi).

$\mathrm{El}$ individualismo es el valor cardinal de las sociedades modernas. El surgimiento del individualismo significará simultáneamente la ceguera ante lo social. La ideología moderna es individualista en la medida en que valora al individuo concebido como sujeto moral, independiente y autónomo e ignora o subordina la totalidad social. Según esta configuración de ideas-valores el individuo posee atributos como la igualdad y la libertad (Dumont, 1987: 23-4) ${ }^{9}$. Este individuo moderno se entiende como sujeto emancipado de lo social, libre de todo orden colectivo e igual a todos los demás seres humanos y en 
cuanto tal la encarnación de la humanidad. Dumont es conciente que es preciso, no obstante, distinguir entre un principio ideal y la realidad de la modernidad pues "una sociedad tal como la concibe el individualismo no ha existido en ninguna parte". Por lo tanto, el individualismo moderno es en realidad una especie de "inconsciencia de lo social" (Tcherkézoff, 1993: 156).

Como ideología destaca en el individualismo moderno la distinción absoluta entre el sujeto y el objeto, la disociación de los valores de las cosas y las ideas, y la primacía de la relación entre el ser humano y las cosas que contraste con el valor que el modelo holista atribuye a las relaciones entre seres humanos. Mientras que en el modelo holista el individuo es una mera entidad empírica subsumida en la totalidad social trascendente, en la modernidad el individuo, sujeto del artificialismo moderno, es dotado de valor absoluto como ser racional y libre. Las cosas sociales, los individuos y sus posiciones, son en si mismos al no parecer estar situados ni constreñidos por principio externo alguno.

En un sentido histórico, este individuo moderno es aquel sujeto en el individualismo igualitario asociado a la concepción universalista del ser humano que adquiere toda su fuerza a inicios del siglo diez y nueve cuando surge la doctrina del sistema libre de mercado y nace una visión de lo social en cuanto consecuencia de una economía autorregulada (Dumont, 1983, 1987). Este individualismo es nominalista en la medida en que dota de realidad al individuo ignorando las relaciones sociales en que está invariablemente atrapado.

En este universo individualista liberal pareciera no tener cabida la jerarquia en el sentido dumontiano ya que el individuo libre es el valor supremo. Según Dumont el escaso eco que tuvo su diagnóstico de la jerarquía como principio unificador del sistema de castas y su insistente confusión con la desigualdad fue una manifestación a la aversión típicamente liberal moderna a la jerarquía", ya que "en la ideología moderna la jerarquía está en el corazón de lo 'impensado"' (Dumont, 1979a: vii-viii). El "valor", vale decir, la jerarquia, la totalidad que 
envuelve o engloba sus elementos, en las ideologías holistas es parte integrante, pero en la ideología moderna el planteamiento jerárquico de la ideología individualista, está segregado, situado en el exterior y por ello pertenece a lo "impensado", es decir, no es tematizado sino tomado como dado (1987: 28 y 279).

La formulación de Dumont es invariablemente compleja pero es a este nivel de análisis donde quizás resida el mayor interés para comprender el culto moderno del individuo y la radical individualización de la alta modernidad. La ideología moderna al disociar el valor de la ideas y de los hechos descompone, a modo típico del individualismo metodológico, la relación original con el todo, con aquella totalidad social en la que las ideas y los hechos están inscritos en realidad. El individuo y su voluntad arbitraria aparecen como valor trascendental de tal modo que la totalidad social "englobante" es expulsada, desconocida. Dicho de otro modo, la configuración moderna es el resultado de la ruptura de la relación de valor, jerárquica, entre el elemento (el individuo) y el todo (la totalidad social). El mundo objetivo aparece constituido por entidades separadas a la imagen del sujeto individual y las relaciones entre ellos son del tipo de una colección (Dumont, 1987: 239-76).

Podría achacársele a este diagnóstico de la defunción ideológica de la conciencia de lo social en la modernidad, como algunos críticos han hecho, una cierta nostalgia por el espíritu comunitario de las sociedades holistas jerárquicas. Dumont rechazó tal imputación de plano. El estudio crítico de la ideología moderna responde a la urgente necesidad de tornar el modelo moderno, cuyo valor supremo son el ser humano y los derechos humanos, mas complejo para dar cabida, por ejemplo, a la diversidad cultural contemporánea (Bruckner, 1992: 68-70; Tcherkézoff, 1993: 144-5). Dumont alude aquí a la controversia contemporánea típicamente francesa en torno al "derecho a la diferencia". Retomaré este tema al final.

Como ya señalé, Dumont coincide con Mauss al igual que con Polanyi que la civilización moderna, el individualismo-en-el-mundo, difiere de 
Revista de Antropologia, São Paulo, USP, 2001, v. 44 nº 2.

modo radical de cualquier otra civilización y cultura (Dumont, 1987). Ahora bien, si la forma holista, "no moderna", representa el "tipo general en vigor en todas partes", resulta imprescindible saber cómo el individuo, en radical oposición a la sociedad como un todo, pudo convertirse en el portador que incorpora de modo exclusivo los valores últimos a tal extremo que se haya llegado a pensar la sociedad únicamente como una colección o juxtaposición de individuos (1975: 167), es decir, es preciso trazar la historia del ascenso moderno del individuo.

No existe acuerdo acerca de los orígenes del individualismo moderno. Unos autores arraigan el concepto moderno del individuo en la Grecia clásica, otros en el Renacimiento, y aún otros en la revolución burguesa. Al contrastar el modelo holista general con el individualista particular Dumont comete algunos deslices taxonómicos evolucionistas (Tcherkézoff, 1994: 203 ss)d. Pero su acometido principal es la difícil tarea de investigar la génesis y el desarrollo de la ideología moderna (Dumont, 1975, 1982, 1987). Dumont no busca explicaciones causales sino que aspira a des-cubrir las tramas ideológicas y las relaciones fundamentales de las que emerge el individualismo cuyos primeros rastros ubica en los primordios del cristianismo, y que posteriormente se desarrollaron y generalizaron con la religión como fermento principal (1987: 36). Una arqueología del surgimiento de nuevas categorías de pensamiento resulta, no obstante, insuficiente. Para fines comparativos hace falta examinar igualmente en cada sociedad "la importancia relativa de los niveles de experiencia y de pensamiento que reconoce(...). En otras palabras, la jerarquia interna de la cultura" (: 21). Dos ejes analíticos entrelazados le sirven, en efecto, a Dumont de hilo conductor para investigar la genealogía histórica de los conceptos modernos. El camino hacia el individualismo moderno occidental consistió en sucesivas separaciones y emancipaciones de los distintos dominios sociales. Por un lado, están las condiciones históricas que permitieron pensar lo "político" y lo "económico" como categorías separadas y ordenarlas de modo jerárquico. Si la forma holista con su arraigo religioso es la modalidad general y anterior, la trayectoria que 
desembocará en el excepcional individualismo como ideología moderna debe iniciarse con la emancipación del poder político de la autoridad religioso asociada a la creación del Estado a la que sigue, a su vez, la emancipación de la economía de mercado como razón suprema en la modernidad. Esta auténtica revolución de valores conllevó, por otra parte, a la emancipación del individuo de sus ataduras tradicionales y su penetración en el mundo social erigiéndose en valor supremo y medida de todas las $\operatorname{cosas}^{11}$. Como resultado, la ideología moderna valora en primer lugar y sobre todo al ser humano individual lo cual implica su igualdad y libertad.

\section{Pero la teoría en la práctica es otra}

Según Dumont, para poder convertir la ideología en objeto de análisis es preciso estudiarla fuera de su contexto aislándola de sus concomitantes (Dumont, 1982: 38). Ésta es la virtud de la comparación antropológica. Pero Dumont se percata de que un tal aislamiento es del todo imposible. Ya bien avanzada la investigación de la modernidad Dumont se preguntar, en efecto, "¿Qué ocurre con la ideología moderna una vez que se pone en práctica"? En el estudio de la India tradicional parecía ser posible comprender las situaciones concretas observables sin solución de continuidad con las ideas-valores tradicionales profesados. Dumont fue bastante criticado por esta descontextualización ${ }^{12}$. En el mundo donde reina el individualismo moderno Dumont es conciente, en cambio, que la igualdad y la libertad no necesariamente convergen en la práctica, su combinación variando según la sociedad (: 14). En la realidad, los principios ideológicos que inspiran el modelo igualitario moderno se suelen realizar de modo muy imperfecto. Caracteriza mas bien a la modernidad, como bien señaló Galey, no la igualdad que asume sino la que profesa (Galey, 1984: xxiii). Pero poca cosa podemos encontrar en Dumont sobre la desigualdad social real ${ }^{13}$. Todos los escritos enfocan la configuración ideológica de la modernidad. 
Aunque para Dumont la ideología moderna "es de cierto modo el reverso de la India" (Dumont, 1991: 8) y el contraste holismo/individualismo caminaría en la misma dirección que la dicotomía evolucionista que habían propuesto Maine entre status y contrato o Tönnies entre Gemeinschaft y Gesellschaft (comunitas y societas), el individualismo liberal moderno en realidad no resulta ser el reflejo invertido de la imagen de la India, es decir, la inversión simétrica del holismo si se contempla la historia política de Occidente de los últimos dos siglos. En especial el totalitarismo y su forma "mas fuerte", el nacionalsocialismo alemán fueron el fracaso mas terrible de los ideales liberales modernos, y no lo son menos sus antecedentes e ingredientes, los nacionalismos y el racismo, sin olvidar sus reencarnaciones contemporáneas.

Pero ello no significa que el individualismo haya sido nada mas que un espejismo. Por el contrario, la ideología liberal es el valor que en circunstancias socio-económicas concretas provocó los totalitarismos. El tratamiento que Dumont da a lo que denomina de graves "incongruencias" entre el ideal individualista igualitaria universalista y las desigualdades de posesiones y poder, los totalitarismos, los nacionalismos y racismos, resulta, no obstante, incompleto, ambiguo e insatisfactorio. Se entrevé aquí una dificultad de vislumbrar y explicar lo que son en realidad contradicciones ideológico-políticas desde una perspectiva estructuralista lévi-straussiana que desconoce intereses colectivos particulares y estructuras de poder. Planeamientos en exceso generales tienden a diluir intuiciones sugerentes.

El totalitarismo, el nacionalismo y el racismo desafían frontalmente la profesión individualista e igualitaria de la modernidad. Aunque Dumont reconozca la "coexistencia" contradictoria del individualismo y su opuesto, el totalitarismo, que además se impone si acaso con más fuerza en la actualidad, se declara incapaz de ofrecer una interpretación en un plano general mas allá de declarar que "si bien la configuración individualista de ideas y valores es característica de la modernidad, no le es coextensiva" (Dumont, 1987: 31). Es cierto que la violencia y el 
culto de la totalidad social, de la nación, obedecen a la necesidad de obtener la sumisión de los ciudadanos en principio libres a los valores fundamentales de los promotores del proyecto totalitario, allí donde está fuera del alcance la subordinación jerárquica (: 24). Pero permanece las interrogantes sobre qué fuerzas socio-políticas motivan el proyecto nacionalista y sobre si las formas de coacción política del individuo tales como el totalitarismo o las concepciones esencialistas anti-liberales del orden social como el racismo, son residuos tradicionales anacrónicos o, por el contrario, constituyen fenómenos que forman parte contradictoria de la propia modernidad $(: 31)^{14}$. Dumont no tiene respuesta para estas preguntas fundamentales sino que alude con algo de ironía derrotista a una suerte de "crisis del paradigma ideológico moderno", que tal vez sea incluso consubstancial a la modernidad (Dumont, 1982: 21). Pero es probablemente mas acertado preguntarse, como lo hace Galey, si no será que la propia ideología moderna secreta la crisis en vez de que ésta sea el síntoma de una crisis de paradigma (Galey, 1984: xxvii).

\section{La perversión del individualismo moderno}

Dumont no habrá logrado formular una teoría general del individualismo moderno que incorporara sus propias contradicciones y, por lo tanto, una perspectiva política. Prefirió experimentar, caminar hacia nuevos horizontes. Existen, no obstante, tres textos suyos, escritos a lo largo de veinte años que todos giran alrededor de los conceptos de valor y de jerarquia que resultan de extraordinario interés y relevancia para pensar la cada vez mas exacerbada contradicción entre el brutal individualismo liberal y las doctrinas y políticas antiliberales exclusivas contemporáneas (Dumont, 1960, 1979, 1980).

Mi primer contacto con la obra de Dumont data de hace unas tres décadas. Yo estaba buscando herramientas para interpretar la compleja lógica de una sociedad esclavista, racista y sexista, la Cuba colonial (Stolcke, 1974). Tuve la suerte de que el profesor e indianista David 
Pocock de Oxford me recomendara la lectura de Homo Hierarchicus. Resultó una revelación. Aunque el libro tratase de un mundo muy distante y distinto de aquel que yo estudiaba, me proporcionó, no obstante, la comparación que yo precisaba para comprender el racismo colonial como ideología característicamente moderna. De especial interés fue en ese momento la crítica de Dumont respecto al reduccionismo socio-céntrico que era habitual entre los sociólogos liberales estadounidenses quiens interpretaban el sistema de castas al igual que la segregación racista en EEUU como formas variadas de estratificación social (Dumont, 1966). Este texto está entre los apéndices de Homo Hierarchicus pero apenas se conoce. La controversia quedó en agua de borrajas. No así la tesis de Dumont sobre el racismo que tiene la virtud duradera de encarar la cuestión de fondo, a saber, el por qué de la discriminación racista en la sociedad moderna. ¿La sociedad individualista moderno no está compuesta por individuos libres de cualquier determinación o coerción "natural" siendo así dueños de su propio destino? ¿Cómo es posible entonces que en ciertos contextos se atribuya el desempeño, la conducta, la inteligencia de un individuo a su dotación "racial"?

Para Dumont el racismo es un fenómeno típicamente moderno porque se trata de una ideología que presupone el propio liberalismo individualista. En la sociedad de castas una doctrina del tipo del racismo no tendría razón de ser. Según el holismo jerárquico como valor supremo la gradación social está en el orden de las cosas que está en sus orígenes y la explica. A diferencia, la sociedad occidental moderna no solamente postula la igualdad y libertad en derecho de los ciudadanos sino que proclama además la igualdad original de todos los seres humanos de modo que la desigualdad resulta ilegítima: "la proclamación de la igualdad ha hecho estallar un modo de distinción centrado en lo social (...) el dualismo subyacente (la distinción cartesiana del espíritu y la materia) conducía, para reafirmar la desigualdad, a poner delante los aspectos físicos" (Dumont, 1970: 325-6). Dumont se refiere aquí a lo que hoy día se suele denominar la "naturalización" de la desigualdad 
social mediante el empleo de supuestos que forman parte del contexto contemporáneo del saber y de la verdad última, como lo es la dicotomía cartesiana naturaleza/cultura. La desigualdad que contradice la tan celebrada igualdad y libertad de los individuos se explica apelando en clave nominalista a insuficiencias o méritos que están en la misma naturaleza de los individuos como, por ejemplo, su "raza", su coeficiente de inteligencia, que son inmutables. Lo novedoso e incluso actualmente rara vez reconocido en Dumont es el haber mostrado que doctrinas discriminadoras, excluyentes y/o jerarquizantes que coartan la profesada libertad individual, sin embargo, por necesidad la presuponen como ideología que postula la igualdad entendida como identidad cum unidad de la especie humana. Resulta lógicamente imposible pensar la segregación o discriminación racial como ideología si no prevaleciese una idea de la unidad e igualdad humana. Resultaría políticamente superflua la descalificación racista si no prevaleciese una ética igualitaria. Como bien reconocía Mauss ya en 1897, "Negar la irreductibilidad de las razas es proponer la unidad del género humano" (citado en Dumont, 1970: 329). En los términos de Dumont, el racismo constituye otra manifestación de la jerarquía que se da en el plano de los valores entre el supuesto universalista de la unidad humana entendida como conjunto indiferenciado de individuos idénticos y, en un nivel subordinado, la discriminación entre éstos de acuerdo a criterios que provee el contexto del saber. Como señalé, Dumont entiende por jerarquía no una cadena de mando o de individuos de dignidad decreciente sino una "relación de englobamiento de su contrario". Desde esta perspectiva, el valor de la unidad humana engloba las ideas racistas porque permite su desafío. El mismo análisis es evidentemente aplicable a las sistemas de sexo/género (Dumont, 1979b: 397-299).

Aunque sea "impensada", la idea de la unidad humana como valor global de la modernidad constituye así una condición imprescindible para que se de el racismo, pero lo es igualdamente, hay que añadir inmediatamente, la desigualdad social que es su razón de ser última. 
Esta tensión o contradicción entre un ideal de unidad humana y los insistentes particularismos excluyentes es la paradoja primordial de la modernidad pues, como escribía Goldberg hace poco: "Cuanto mas universalistas son los compromisos de la modernidad, tanto mas abierta y determinada está por la especificidad racial y el exclusivismo racista y sus parecidos" (Goldberg, 1993: 4) ${ }^{15}$. Y ello es así porque la ideología individualista liberal moderna promete lo imposible, la igualdad en libertad. El modo de neutralizar las consecuencias políticas que pueden resultar de la contradicción entre el ideal individualista liberal y las desigualdades socio-económicas realmente existentes consiste en atribuir esta desigualdades, traducidas en "fracasos" personales o de grupo, a deficiencias "innatas", de esta manera "naturalizándolas" y negando su real arraigamiento en relaciones socio-políticas.

Para concluir quiero volver a la tercera dimensión del pensamiento dumontiano respecto a la antropología social como forma de conocimiento. Si la antropología social asimismo es un invención radical moderna subyace también a ella una relación de jerarquía entre universalismo e individualismo o particularismo. La comparación intercultural que realiza la antropología exige la diferencia y simultáneamente supone la unidad de la especie humana (Dumont, 1987: 207-37). Sin el valor de que el individualismo moderno dota a la unidad de la humanidad las diferencias resultarían imperceptibles por irrelevantes pero las desigualdades también serían inexpugnables. El problema constitutivo de la antropología social como tipo de conocimiento moderno es, así, la tensión entre lo universal y lo particular en cuanto ideas-valor. Las diferentes maneras como antropólogas/os se han movido entre estos dos polos varió a lo largo de la historia moderna pero el dilema de cómo cuadrar el círculo de la "apercepción" de las diferencias con la unidad y solidaridad humanas no sólo sigue eludiéndonos, sino se ha agudizado con la globalización progresivamente mas desigual.

El mérito intelectual de Dumont es doble: nos permite comprender bastante mejor la perversidad engañosa del individualismo moderno 
en su poderosa dimensión ideológica y política, pero nos muestra al mismo tiempo que la antropología puede, si lo desea y se empeña en ello, responder al "gran desafío contemporáneo para los valores modernos (que) está constituido por la exigencia, o el problema, de la solidaridad humana a escala mundial, de la justicia - particularmente en el plano económico - en las relaciones entre pueblos y Estados" (: 214).

\section{Notas}

1 Antes de la fundación, en 1925, del Instituto de Etnología de la Universidad de Paris, adscrito al Musée d'Ethnographie du Trocadero, Marcel Mauss había enseñado historia de la filosofía y de las religiones indias anteriores al hinduismo en la École des Hautes Études en Sciences Sociales; era también un especialista en sánscrito. En el Instituto de Etnología amplió su docencia y formación de investigadores al campo de las categorías de pensamiento como fenómenos interdependientes con la sociedad.

2 Menciono aquí solamente el episodio mas trágico y brutal que sobrevino a los etnólogos del recién creado Musée de l'Homme instalado en el nuevo Palais Chaillot en 1938 y era dirigido por el americanista Paul Rivet. Cuando los Nazis ocuparon Paris en junio de 1940, Anatole Lewitzky, de procedencia rusa y especialista en shamanismo siberiano, ya había sido desmovilizado. De vuelta al Musée organiza con Boris Vildé e Ivonne Odon la red de resistencia del Musée, la primera que surgió en la Francia ocupada. A principios de 1941 las SS rodearon el Palais Chaillot, registran el museo y detienen primero a Lewitzky y a continuación a los demás miembros de la red que son procesado un año mas tarde. Ledwitzky, Vildé y los restantes cinco miembros fueron condenados a muerte y fusilados en el Mont-Valérien. Las mujeres fueron indultadas (Hollier, 1995: 578-9). Paul Rivet huyó a Colombia donde permaneció hasta la liberación de Paris (Duarte, 1960). Como es sabido, Claude Lévi-Strauss también tuvo que ir al exilio. Su primera opción había sido regresar al Brasil pero el gobierno populista de Vargas le negó el necesario visado por ser judío y así se acogió al esquema que la Fundación Rockefeller había organizado para llevar a Estados Unidos científicos europeos amenazados por los Nazis.

3 En esos años de la inmediata posguerra Louis Dumont desarrolló una actividad etnológica intensa. Fue nombrado editor de la revista Mois d'Ethnographie 
Revista de Antropologia, São Paulo, USP, 2001, v. 44 nº 2.

Francaise. Descubrió la escuela alemana de etnología y emprendió la re-edición de su obra para rehabilitarla. Al regresar, Lévi-Strauss le encargó mecanografiar su manuscrito sobre los artefactos culturales de los Bororo y Dumont leyó el manuscrito de Las Formas Elementares del Parentesco a petición del primero. Escribía también bajo pseudónimo para la revista de la vanguardia del cine Cine Liberté y fue amigo del director Jean Renoir. Agradezco estos detalles biográficos a JeanClaude Galey quien fue el último discípulo de Dumont.

4 Diversas definiciones de los conceptos de ideas-valores e ideología se suceden en los escritos de Dumont. Emplea la noción ideas-valores para las formas de pensamiento "no modernas" en las que resultaría imposible separar ideas y valores, en contraste con la modernidad que precisamente las separa (Dumont, 1987: 277). Ideología - que no es estrictamente intercambiable con el concepto anterior - se refiere a un conjunto de representaciones, seguramente muy complejo: "Ninguna ideología en su totalidad puede ser considerada 'verdadera' o 'falsa' pues ninguna forma de conciencia es nunca completa, definitiva o absoluta (...) todas las formas de conciencia son semejantes en el sentido de que ninguna opera sin una 'reja' a través de la cual tomamos conciencia de lo dado y al mismo tiempo dejamos de lado una parte de ese dado (...). Todo lo que se puede afirmar sobre la relación entre lo que nos representamos y lo que 'ocurre de hecho' es que tal relación es necesaria y que no es de identidad (...) es todo lo que es socialmente pensado, creído, actuado, partiendo de la hipótesis de que hay una unidad viva en todo esto, escondida bajo nuestras distinciones habituales. La ideología no es aquí un residuo, es la unidad de la representación, una unidad que no excluye por lo demás la contradicción o el conflicto" (Dumont, 1982: 289 y 33-4).

5 La deuda intelectual de Dumont con Lévi-Strauss con respecto a la concepción de "estructura" es clara; la noción de "estructura" es aplicable a aquellos sistemas en los que la estrecha interdependencia de sus elementos no permite aprehenderlos en si mismos sino únicamente en su relación recíproca (Dumont, 1955: 14).

6 Dumont ya había dado a conocer y debatido a lo largo de la década precedente su modo característico de interpretar la civilización de la India en la influyente revista Contributions to Indian Sociology, creada por él en 1957 junto con David Pocock, su discípulo a principio de los años cincuenta cuando él era docente en el Instituto de Antropología Social de Oxford, el mismo año en que también fundó el Centro de Estudios de la India y de Asia del Sur en la Ècole des Hautes Études en Sciences Sociales, Paris, donde fuedirecteur d'études a partir de 1955. 
7 "El renunciamiento en las religiones de la India" apareció en los Archives de Sociologie des Religions, n. 7, en 1959, pp. 45-69; una versión inglesa fue publicada en Contributions to Indian Sociology, vol. IV, 1960, pp. 33-62 (Dumont, 1970: 329).

8 Según su glosario la jerarquía se distingue del poder o mando y es un orden resultante del empleo del valor. La relación jerárquica elemental (u oposición en el sentido de distinción intelectual) es aquella que se da entre un todo (o un conjunto) y un elemento de ese todo (o conjunto) (Dumont, 1987: 278).

9 Dumont se dedicó a la interpretación del individualismo moderno durante tres décadas. Su primer texto dedicado expresamente al tema fue "The modern conception of the individual" publicado en 1965. En 1977 apareció Homo Aequalis. Génesis y apogeo de la ideología económica, consagrado a la historia de las ideas de distinguidos pensadores modernos en torno al dilema individuo-sociedad, igualdad-libertad. En 1983 publica la compilación de Ensayos sobre el individualismo. Una perspectiva antropológica sobre la ideología moderna, y en 1991, ve la luz, finalmente, L'idéologie allemande. Homol aequalis II. France-Allemagne et retour.

10 Las apasionadas críticas que provocó Homo Hierarchicus tuvieron como ejes 1) la ordenación jerárquica de la religión y la moral por encima del poder temporal por Dumont en el caso de la India, 2) su denuncia del sociocentrismo occidental en el análisis convencional del sistema de castas como una forma de estratificación social, 3) la crítica materialista a su "idealismo" y, 4) el que Dumont no hubiese prestado atención a las realidades sociales y políticas contemporáneas (Dumont, 1979: i-xxxix; Béteille, 1986: 121-34).

11 Dumont analizó el ascenso del individualismo moderno en varias ocasiones. Indico aquí las fechas de publicación originales de sus escritos al respecto. El primer texto en orden cronológico trata del progreso del individuo a partir del siglo trece por un proceso de escisiparidad mediante el que el dominio englobante de la religión da origen a la categoría nueva de lo político y la institución del Estado conquista las atribuciones de la Iglesia (Dumont, 1975, 1970). A seguir Dumont retrocede en el tiempo para describir como el individuo cristiano que en los primeros siglos del cristianismo era en principio extraño al mundo terrenal se encuentra cada vez mas implicado en él (Dumont, 1987) después de haber descrito cómo, al igual que la religión dio origen a lo político, en la etapa siguiente, a partir del siglo diez y siete, lo político daría origen a la emancipación de la categoría de lo económico y al apogeo del individualismo moderno (Dumont, 1970). 
Revista de Antropologia, São Paulo, USP, 2001, v. 44 nº 2.

12 Béteille, en un excelente artículo crítico insiste, por un lado, en lo problemático que es limitarse en el análisis antropológico incluso de la India a los valores profesados en las retóricas religiosas y los textos clásicos pues éstos deben ser situados en su contexto social que puede muy bien contradecirlos, y, por otro, muestra que los valores de igualdad y libertad lejos de ser inseparables como postula Dumont, resultan muchas veces contrarios (Béteille, 1986: 121-34; Dumont, 1979). La ofensiva neo-liberal es la mejor prueba de ello.

13 Dumont sugiere que en contraste con el holismo que incluye a las castas subordinadas, los valores igualitarios exigen que sean reducidas o abolidas las relaciones desiguales de poder y posesión excluyendo a los desposeidos. Pero, si es inadecuado calificar la desigualdad social como "estratificación social" a la manera de la sociología liberal de EEUU, interpretarla, por ejemplo, como "residuo de jerarquía" no resulta mas clarificador (Dumont, 1982: 23).

14 En el provocador análisis redactado en 1967 de Mein Kampf, el ideario de Adolf Hitler, Dumont coincide con la tesis de Arendt de que el holocausto a que condujo el nacionalsocialismo alemán es un fenómeno típicamente moderno. En su momento esa interpretación fue objeto de las mas severas críticas dentro como fuera de la diáspora judía. La modernidad del nacionalsocialismo residía para Dumont en que fue en realidad un pseudo-holismo, un holismo particularista, pues la pretensión nazi de acceder a la Volksgemeinschaft, la comunidad del pueblo, se tradujo en el fomento del antagonismo racial en la forma del anti-semitismo; por consiguiente, "el racismo resulta aquí de la disgregación de la representación holista por el individualismo" (Dumont, 1987: 183; Arendt, 1964; Baumann, 1989).

15 Dumont sostiene, con razón, que la reivindicación simultánea por parte de grupos sociales discriminadas y/o excluidos como las mujeres y los homosexuales, de la igualdad y de su reconocimiento y respeto como "otros" diferentes, es una imposibilidad pues el reclamar la igualdad significa ignorar la diferencia. El reconocimiento de las diferencias en cuanto tales tendrfía inevitables consecuencias jerárquicas en la medida en que en el marco de los valores modernos ese reconocimiento necesariamente significaría una gradación de los diferentes de superior a inferior mismo que el orden podría ser invertido (Dumont, 1987: 273-4). Es decir, la ideología moderna no tendría cabida para la diferencia reconocida como tal sin consecuencias jerárquicas. Esto es al menos discutible pues supone que diferencia invariablemente significa desigualdad, una idea que precisa forma parte del ideario liberal moderno. 


\section{Bibliografía}

ARENDT, $\mathrm{H}$.

1964 Eichmann in Jerusalem: a Report on the Banality of Evil, Nueva York, Viking Press.

BAUMANN, Z.

1989

Modernity and the Holocaust, Londres, Polity Press.

BERARD, P.

1982

"Louis Dumont: anthropologie et modernité", Nouvelle École, vol. 39: 95-115.

BÉTEILLE, A.

1986 "Individualism and Equality", Current Anthropology, vol. 27(2), Apr.

1999 “Obituary: Louis Dumont (1911-98)”, Economic Political Weekly, 2-9 Jan.

BRUCKNER, P.

"Un entretien avec Louis Dumont: le grand comparateur", Le Nowvelle Observateur, n. 1417, 2-8 Jan.

COPPET, D. DE

1992

"Comparison, a universal for anthropology: from 're-presentation' to the comparion of hierarchies of values", KUPER, A. (Ed.), Conceptualizing Society, Londres, Routledge, pp. 59-74.

DUARTE, P.

1960 Paul Rivet, por ele mesmo, São Paulo, Anhembi.

DUMONT, L.

La Tarrasque, Paris, Gallimard.

1955

"For a sociology of India", Contributions to Indian Sociology, vol. I.

1957 Une sous caste de l'Inde du Sud. Organisation sociale et religion des Pramalai Kallar, Paris/Haya, Mouton.

1959

"El renunciamiento en las religiones de la India", Arcbives de Sociologie des Religions, n. 7: 45-69, ene.-jun. 
Revista de Antropologia, São Paulo, USP, 2001, v. 44 nº 2.

1960 "Caste, race et stratification sociale", Cabiers Internationaux de Sociologie, vol. XXIX: 91-112.

1966 Homo bierarchicus. Le système de castes et ses implications, Paris, Gallimard.

1970 Homo bierarchicus. Ensayo sobre el sistema de castas, Madrid, Aguilar.

1975 "On the comparative understanding of non-modern civilizations", Daedalus, vol. 104(2), Spring.

1979a "Préface et Postface", in Homo Hierarcbicus, Paris, Gallimard.

1979b "Vers une théorie de la hiérarchie", "Postface" in Homo Hierarchicus, Paris, Gallimard.

"On value", Proceedings of the British Academy, Londres, vol. XVI.

Homo Aequalis. Génesis y apogeo de la ideología económica, Madrid, Taurus.

"Préface", in POLANY, K. , La grande transformation, Paris, Gallimard.

Ensayos sobre el individualismo, Madrid, Alianza Editorial.

“Prix Tocqueville”, Esprit, n. 129-130, ago.-sep.

La civilización india y nosotros, Madrid, Alianza Editorial.

1990

"Sur l'idéologie politique française. Une perspective comparative", Le Débat, n. 58, Jan.-feb.

L'idéologie allemande. France-Allemagne et retour. Homo Aequalis II, Paris, Gallimard.

DROIT, R.-P.

1998

"Louis Dumont: l'auteur de recherches sur le holisme en Inde et l'individualisme en Europe", Le Monde, 26 nov.

GALEY, J.-C. (ED.)

1984 Différences, valeurs, biérarcbie. Textes offerts à Louis Dumont, Paris, Éditions de l’École des Hautes Études en Sciences Sociales.

GALEY, J.-C.

"Présentation", in Différences, valeurs, hiérarchie. Textes offerts à Louis Dumont, Paris, Éditions de l'École des Hautes Études en Sciences Sociales. 

Anthropologist, vol. 102(2): 324-8.

GINGRICH, A.

1998

"Review Essay: Toward an anthropology of Germany: A culture of moralist self-education? (Dumont's German Ideology)", Current Anthropology, vol. 39(4) Aug.-Oct.

GOLDBERG, D. T.

1993

Racist Culture. Philosophy and the Politics of Meaning, Oxford, Blackwell.

GOODY, J.

1996

The East in the West, Cambridge, Cambridge University Press.

HOLLIER, D.

1995

Le Collège de Sociologie, 1937-1939, Paris, Gallimard.

POLANY, K.

1944

The Great Transformation, Nueva York.

STOLCKE, V.

Marriage, Class and Colour in Nineteenth - Century Cuba, Cambridge, Cambridge University Press.

TCHERKÉZOFF, S.

“'L'individualisme' chez Louis Dumont et l'anthropologie des idéologies globales. Genèse du point de vue comparatif', Anthropologie et Sociétés, parte 1, vol. 17(3).

1994

“'L'individualisme' chez Louis Dumont et l'anthropologie des idéologies globales. Genèse du point de vue comparatif', Anthropologie et Sociétés, parte 2, vol. 18(1).

WEILL, N. 
ABSTRACT: As a starting point for discussing Louis Dumont's notion of individualism, this article uncovers two intersecting perspectives in the author's work: one, methodological, pertaining to the anthropological study of Indian Civilization, and, the other, theoretical, referring to the relation between individual and society, in Maussian terms. An analysis of Dumont's structural and comparative approach leads us to see how individualism, while ideologically at odds with hierarchy, as exemplified by the Indian caste system, may, nonetheless, be found to be quite similar to its ideological opposite in respect to logical properties which pertain to sociological englobement and veiling of values and practices. Thus, one sees how there is room within individualistic systems, notwithstanding their liberal and equalitarian features, for totalitarian and racist ideologies, the perversions of hierarchy which treat inequality on assymetrical sociological planes as "nature".

KEY-WORDS: individualism, hierarchy, equality, comparative and structural analyses.

Recebido em junho de 2001. 